\title{
Jute Crop Discrimination and Biophysical Parameter Monitoring Using Multi-Parametric SAR Data in West Bengal, India
}

\author{
Dipanwita Haldar, Chakrapani Patnaik, Manab Chakraborty \\ Space Applications Centre, Ahmedabad, India \\ Email: dipanwita@sac.isro.gov.in
}

Received 1 July 2014; revised 20 August 2014; accepted 23 September 2014

Copyright (C) 2014 by authors and OALib.

This work is licensed under the Creative Commons Attribution International License (CC BY).

http://creativecommons.org/licenses/by/4.0/

(c) (i) Open Access

\section{Abstract}

The article highlights the results of a study carried out to understand the Synthetic Aperture Radar (SAR) response to the second most important fibre crop of India i.e. Jute at $C$ and $L$ band frequency and at multiple polarizations. Methodology has been well established to classify jute crop using 3-date multitemporal HH SAR data and is being used for national level forecast in India. Performance comparison of single polarization $(\mathrm{HH})$ multi-date versus dual-polarization 2-date data from Radarsat (both dual-pol $\mathrm{HH} / \mathrm{HV}$ and quad-pol) was evaluated. Three-date HH polarization (May, 05, May 29 and June 22) data had results comparable to two-date HH/HV data with around $90 \%$ accuracy. Correlation between backscattered signals and crop height shows that L-band signal has high correlation with crop height particularly in the peak or advanced crop growth stage as compared to C-band. Also backscatter variation with percent area cover has been investigated. Both plant height and area cover show stronger dependence to cross-polarization backscatter. Biophysical parameters viz. crop height and vigour map has been generated which will aid in monitoring growth and yield potentials.

\section{Keywords}

Jute Identification, Backscatter, Multi Polarization Data, Multifrequency SAR, Plant Biophysical Parameters, Plant Height, Plant Vigour

Subject Areas: Bioengineering, Biogeography, Plant Science

\section{Introduction}

Jute is one of the important fibre crops in India having a good share in foreign exchange. It sustains country’s

How to cite this paper: Haldar, D., Patnaik, C. and Chakraborty, M. (2014) Jute Crop Discrimination and Biophysical Parameter Monitoring Using Multi-Parametric SAR Data in West Bengal, India. Open Access Library Journal, 1: e817.

http://dx.doi.org/10.4236/oalib.1100817 
jute manufacturing industry and provides gainful employment to a large segment of population. Assam, Bihar, West Bengal and Orissa are the major jute growing states in the country, which account for $98.2 \%$ of area and 98.5\% of the production in the country [1]-[3]. Jute thrives best in the warm and wet climate (monsoon climate). Taxonomically it belongs to family Tiliaceace (earlier) and now is classified in Malvaceae (Grewoideae). Two commercially important species are cultivated in India; they are Corchorus olitorius (Tossa jute fibre) and Corchorus capsularis (White jute fibre). The jute fibre is a ligno-cellulose fibre that is partially a textile fibre and partially wood.

Sensitivity of SAR to canopy geometry and moisture can be suitably exploited not only for crop discrimination and crop area but also to assess crop condition. Differential attenuation of grain crops of HH versus VV-polarization has been studied by [4] [5]. Shallower incidence angles (near 40 degree) increase the path length through vegetation thus maximizing the crop response and better classification capabilities ([6] [7]). [8] reported that attenuation through vegetation is proportional to vegetation water content. The potential of multi-temporal SAR data for rice crop monitoring have been demonstrated by a number of investigators ([9]-[16]). [17] Macelloni et al. (2002) also found similar results in modeling the backscatter for the wheat crop during its various growth stages and estimated the cover under wheat. Canopy has been modeled as a sparse layer of randomly oriented particles (leaves, stalks etc.). Using all L-band linear polarizations, corn, soybeans, cereals, and hay-pasture were classified to an overall accuracy of $70 \%$. A more temporally rich C-band data set provided an accuracy of $80 \%$ [17]. [18] studied the growth progress as manifested by change in backscatter in dual-polarized PALSAR data. [19] [20] estimated the area under rice crop under different management and cultural practices using ERS SAR data. It has led Satellite remote sensing based crop acreage estimation as one of the reliable methods towards large area crop acreage estimation. The technical precision of such procedures has improved through years and at present is accepted to meet the requirement of routine gathering of timely information on crop prospects.

Out of the four major jute producing states of India viz. West Bengal, Bihar, Assam and Orissa, most of the country's jute area and production (about 90\%) comes from West Bengal and Bihar. The crop being grown in pre-kharif (pre-monsoon) season, optical remote sensing data is not available during the later stages (June and July); hence SAR data was acquired for the study. A successful district level study using multi-temporal SAR data during 2006 and 2007 for four major jute growing districts (Murshidabad, Nadia, Cooch Bihar and Jalpaiguri) of West Bengal has enabled the initiative for operational inventory of jute crop in India. Jute classification accuracy of around 92 percent was achieved for training sites [21]-[23]. In this study we demonstrate jute crop identification and classification using three-date SAR data by identifying and examining the temporal growth profile. The rainfed cultivation and varied management practices of jute crop in the Indian sub-continent results significant year to year fluctuations in crop area and hence timely and accurate information is a mandate for decision makers.

\section{Study Region}

The study area consisted of the major jute growing district of West Bengal i.e. Murshidabad, India. The dominant cropping pattern is paddy-jute-paddy. This has been confirmed by repeated ground data collection in this region-Murshidabad district of west Bengal over a period of last five years. The physiography is plain land, which is part of the Indo-Gangetic plain. The jute season lasts from beginning of April to end of July or sometimes till August depending on availability of ample amount of clean water for retting. The crop is harvested when it is around 120 - 130 days old [24]. Ample amount of clean flowing water is a major limitation in many jute growing regions which is a requirement for retting. The jute belt is thus located far from the industrial zones where clean free flowing water is available. Industrial belt in nearby areas are short of clean free flowing water which is must for the post-harvest processing of the crop. The data acquisition plan were made keeping in mind the normal dates of sowing.

\section{Data Used}

Three sets of SAR data at different crop growth stages have been planned based on the crop calendar. The first date coincided with the initial crop stage (25 - 30 day crop corresponding to May beginning), the second date coincided with the peak vegetative stage (May end or June beginning) and the third date was acquired before the harvest of the crop (June end to July beginning). Radarsat-2 Wide Beam (W2) multi-date dataset [C-band-5.405 
$\mathrm{GHz}$, HH-polarization, incidence angle range $30^{\circ}-39^{\circ}$ and 2-looks] have been used as data source for the major jute growing districts. The W2 data has been selected for its large area coverage (150 km swath) and acceptable pixel spacing $(10 \mathrm{~m})$. The data acquisitions were made from May 05, to June 22, 2010. In addition 2-date polarimetric data has been acquired in July-August, 2011 in matured crop stage. In addition ALOS PALSAR (L-band, $1.27 \mathrm{GHz}$ ) dual polarization FBD data of June and July, 2010 have also been aquired. Ancillary data on rainfall was collected. Jute is mostly rainfed crop, dependent on pre-monsoon showers for water requirement.

\section{Methodology}

\subsection{Collection of Ground Truth (GT) Information}

The crop is sown during last week of March to mid April. The data acquisition was planned coinciding with the crop season. Ground truth data were collected synchronous to the passes of the satellites. The coordinates of GT sites were noted using Global Positioning System (GPS) receivers. During the ground truth campaign, crop parameters like extent, age, vigor, height, density and biomass at selected sites were measured and soil parameters like moisture and roughness were noted qualitatively. As the economic yield is phloem fibre which is vegetative, plant height estimation and relation with backscatter would be closer than total biomass with backscatter which includes leaves also. Care was taken to select sites, which had at least 3 hectares in contiguity. The crop, soil and field related parameters are tabulated in Appendix 1. Such information was collected for the entire study region.

\subsection{Preprocessing of SAR Data}

Pre-processing of Radarsat Wide Beam (W2) data was carried out using PCI Geomatica ver 9.1 image processing software. The data was downloaded along with the header and ancillary information of incidence angles. Speckle suppression was carried out using Enhanced Lee filter with a $5 \times 5$ window size [19] (Chakraborty et al, 1997). The data calibration was carried out using the antenna gain and offset values. Then geo-referencing of all the dates' data was carried out using second order polynomial model (Figure 1). The multi-temporal co-registered SAR data was used to identify the jute crop and finally proceed for classification. The ground truth sites were marked on the image and the multi-temporal signatures were analyzed from the mean and standard deviation of the backscatter. Also a multitemporal set was prepared for three-date dual-polarization (HH/HV) datasets. The data covered the initial crop growth till the post vegetative growth stage. For the ALOS-PALSAR data processing was carried out in SARSCAPE module of ENVI-4.4. Preprocessing steps were similar to the Radarsat data. Calibration was done to get the backscatter image. Finally GT information was overlaid and analysis was carried out.

\subsection{Data Classification}

Data classification was carried out with hierarchical decision rule classification technique. Identification of the different land cover classes was done based on the statistics of mean backscatter and deviation from mean. After
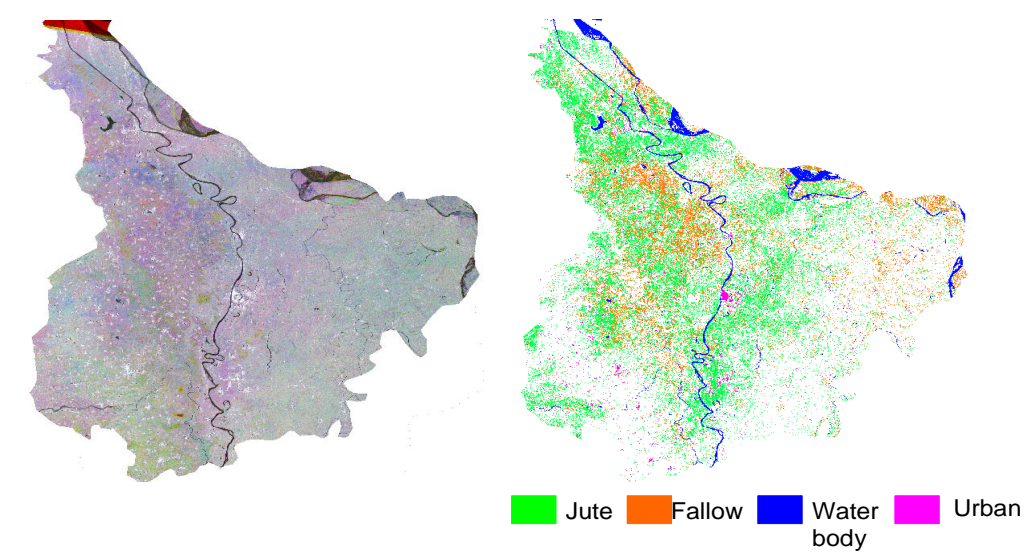

Figure 1. FCC (R: May 04; G: May 29 and B: June 22, 2010) and classified image of Jute crop and other land features in Murshidabad dist (West Bengal). 
masking out the water, homesteads, urban and fallow areas by the decision rule classification, the vegetation area was then discriminated into jute and non-jute areas based on the temporal backscatter response. At few sites during the first date of pass, summer rice (rabi rice) is coexistent but it gets harvested just after first pass or before second date of satellite pass. Therefore, second and third date data at these sites gives fallow signature in the $1^{\text {st }}$ date summer rice areas. The third date may give land preparation or puddling signature for the next season kharif rice. The understanding of the interaction of radar with jute crop and the knowledge of plant morphology, cultivation practices and field environment were used for development of the decision rules. The varying ground conditions and soil moisture levels were considered while framing the decision rules. Other kharif heavy foliage crops like sugarcane and maize have a different temporal profile than Jute. Sugarcane is a long duration crop of one to one and half year duration and can be monitored using optical data. Maize is generally sown throughout the country with the onset of monsoon while Jute is sown during end March to April, thus it is in post peak vegetative stage in July when maize is sown.

The confusion matrix generated was used for the assessment of the accuracy of classification. Apart from the conventional three date HH-data classification, 2-date (May, 09 and May, 29) HH/HV dual-polarization based classification was also performed. A decision rule based model was coded using the dual-polarization backscatter to classify the jute area. The polarization ratios in SAR domain like vegetation indices in optical data reflect the changes synergistically and are found to depict crop conditions like height, density, vigour and biomass [25]. The co- and cross polarization ratios as depicted below gives the measure of the change in VV polarization or $\mathrm{HV}$ polarization with respect to $\mathrm{HH}$ polarization. The depolarizing and repolarizing capability of the target is a measure of the volume scattering component of the target [26].

$$
\begin{aligned}
& \text { Co-polarization Ratio }(\mathrm{Co}-\mathrm{PR})=\sigma_{\mathrm{VV}}^{\circ} / \sigma_{\mathrm{HH}}^{\circ} \text { or } \sigma_{\mathrm{HH}}^{\circ} / \sigma_{\mathrm{VV}}^{\circ} \\
& \text { Cross polarization ratio }(\mathrm{Cr}-\mathrm{PR} \text { or XPR })=\sigma_{\mathrm{HV}}^{\circ} / \sigma_{\mathrm{HH}}^{\circ} \text { or } \sigma_{\mathrm{HH}}^{\circ} / \sigma_{\mathrm{HV}}^{\circ}
\end{aligned}
$$

Backscatter and height relation was developed by studying the three date data in terms of variation of backscatter with variation in plant height. A regression was developed using second and third date data when soil background effects are assumed to be negligible and additionally HV backscatter was added to derive the plant height map. Cross polarization ratio was used as a second input and point biomass observation to derive a plant vigour map for the study area.

\section{Results and Discussion}

\subsection{Role of Dual Polarization}

In absence of vegetation, soils produce prevailing surface scattering. The HH-response depends on the soil moisture and the surface roughness values. A low (in theory null) backscatter in HV polarization (crosspolar) is observed in this stage. Vegetation growth is associated with the presence of near-vertical cylindrical elements (main stems, trunks) and inclined elements (leaves, secondary stems). Near vertical cylinders produce doublebounce reflections which increase in the like polarizations (HH and VV backscatter), while leaving the cross polar (HV) component low. Ensembles of inclined disc- or cylinder-shaped elements (leaves and stems) produce volume scattering, with a substantial increase of cross polar component due to the depolarizing and repolarizing nature of the canopy.

There is increase in backscatter in both HH and HV with crop growth in phenological cycle [27]. HH backscatter may either increase with crop growth or soil moisture and soil roughness fluctuations. Here comes the role of cross-polarization HV backscatter which is solely due to volume scattering or multiple scattering and depicts increase in vegetation biomass. Soil roughness was found to be less than 0.6 (ks) in most part of the growing season. " $\mathrm{S}$ " is the RMS height and $\mathrm{k}$ is the wave number. As the surface roughness was below the C-band SAR sensitive zone, variation in HV backscatter is solely due to increased volume scattering in the vegetation which is responsible for depolarization in H-polarization and repolarization in V-polarization. A decision rule based model was coded using the dual-polarization backscatter to classify the jute area and it improved the classification by taking into account the commission error which occur using 2-date $\mathrm{HH}$ data only.

\subsection{SAR Temporal Signature of Jute and Associated Landcovers}

The unique SAR signature of various land cover classes makes jute crop separable from the non jute areas. High 
backscatter of -3 to $5 \mathrm{~dB}$ characterized the urban areas and homesteads in SAR data. These areas appeared bright in all the dates with very little variation in mean backscatter. Similarly very little change in backscatter was observed from forests. Low backscatter of less than $-18 \mathrm{~dB}$ characterized open water bodies like river, ponds and lakes. Backscatter of the fallow fields varied due to presence of grasses, crop residue and moisture status. In the initial stages the backscatter from the soil surface for the freshly sown jute crop dominates, in the field. As the plant develops, the radar backscatter increases due to volume scattering from the vegetation. The non-jute areas such as water, fallow, forest homestead and urban could be delineated from the jute areas based on the evaluation of temporal backscatter. Backscatter from jute areas though has a low dynamic range of about $3 \mathrm{~dB}$, but can be separated from other land cover classes. The backscatter decreases from first to second date and increased from second to the third date. High soil moisture and or roughness just prior to sowing resulted in high backscatter in the first date data. A consistent dip attributed to the canopy attenuation in second date varying between 1 to $3 \mathrm{~dB}$ was observed. The bare soil contributions give the way to plant component as the plant grows, the fraction of the stalk - ground interaction increases subsequently [23]. During the third date, canopy was green and maximum number of leaves was present (increased number of scatterers) which increased the third date backscatter. These observations were made during the field campaign carried out for ground truth data collection.

\subsection{Data Classification}

Based on the hierarchical decision, jute and other associated land cover were classified. The FCC and classified image of Murshidabad Dist is seen in Figure 1.

The zoomed up view of a part of the study area is seen in the Figure 2. The FCC shows the pink and magenta areas which are predominantly jute crop. This colour tone indicates a dip in second date. Green graphic denotes the classified overlay from 3-date HH-backscatter. The red overlay shows the classified crop using 2-date $\mathrm{HH}$ backscatter only. This entails commission of over $40 \%$ due to over-classification in the non jute areas and signature mixing with bare and moist soil due to fluctuation in soil moisture status.

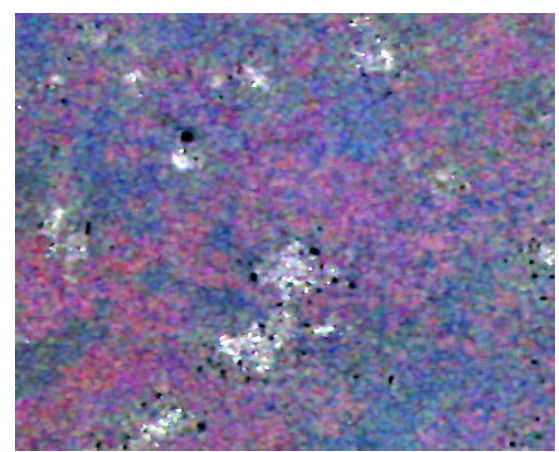

(a)

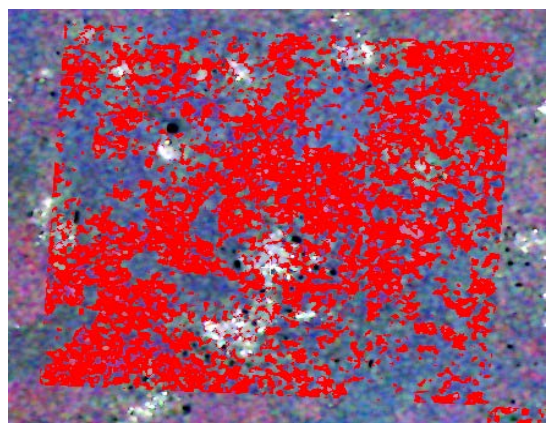

(c)

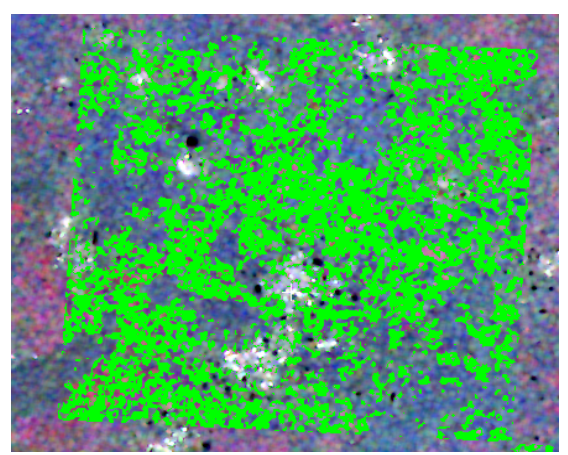

(b)

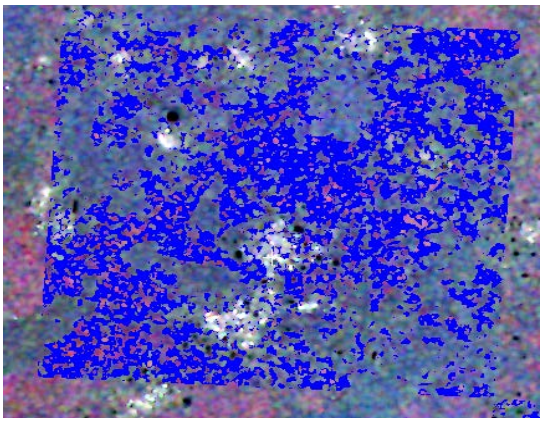

(d)

Figure 2. Clockwise from top-left (a) FCC HH data of May 05, May 29, June 22, 2010; (b) Green: Jute map from 3 date HH data; (c) Red: Jute from 2 date HH (Over-classification of 40\%); (d) Blue: Jute from 2 date (May, 05 and May, 29) HH/HV and XPR (Cross Pol. Ratio) Correct classification in $91 \%$ area. 
This over estimation can be taken care by conjunctive use of $\mathrm{HV}$ data with $\mathrm{HH}$, the increase in $\mathrm{HV}$ backscatter can be attributed to only change in volume scattering and improves the classification accuracy to $91 \%$ as seen by the blue overlay.

\subsection{Plant Biophysical Parameters}

Plant height and area cover are easily measurable by non-destructive methods and these were found to have correlation with backscatter (Figures 3(a)-(d). These biophysical variables were analyzed with backscatter for dual polarization - three date's data. Cross polarization backscatter is found to relate better to plant height as seen by a higher $\mathrm{R}^{2}$ (Figure 3(a) and Figure 3(b)). Study of the variation of backscatter with plant height showed that HV backscatter is strongly related to backscatter in both $\mathrm{C}$ and L-band as compared to HH-backscatter. A similar exercise to Percent area cover is also better regressed to cross-polarized backscatter than like polarized backscatter (Figure 3(c) and Figure 3(d)). Correlation between backscattered signals and crop height showed that L-band signal showed high correlation with crop height particularly in the advanced crop growth stage as compared to C-band (Figure 4). The penetration of longer wavelength is able to retrieve information from deeper canopy levels as compared to shorter wavelength (C or X-band). C-band is seen to attain a plateau quicker than L-band in both like and cross-polarization (Figure 4(a) and Figure 4(b)). C-band VV polarization shows even an earlier saturation due to higher coupling with the vertical plant parts resulting in attenuation loss of the signal.

The relationship of plant height (at sampled locations-Figure 5(a) with backscatter in C-band using the regression model was inverted to create the plant height map Figure 5(b) for the entire area at unsampled locations. This approach is area specific and works for peak vegetative stage (mid July onwards) when crop cover is $95 \%-100 \%$. Under this dense vegetation condition the soil contribution is assumed to be negligible at C-band. At lower frequency or at earlier stage of the crop such relations should be adjusted for soil background by using semi-empirical approach or deterministic models (Attema and Ulaby, 1978).

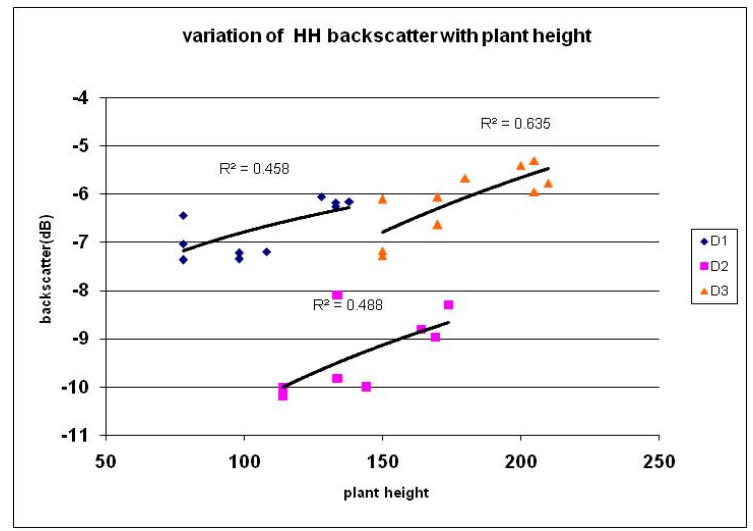

(a)

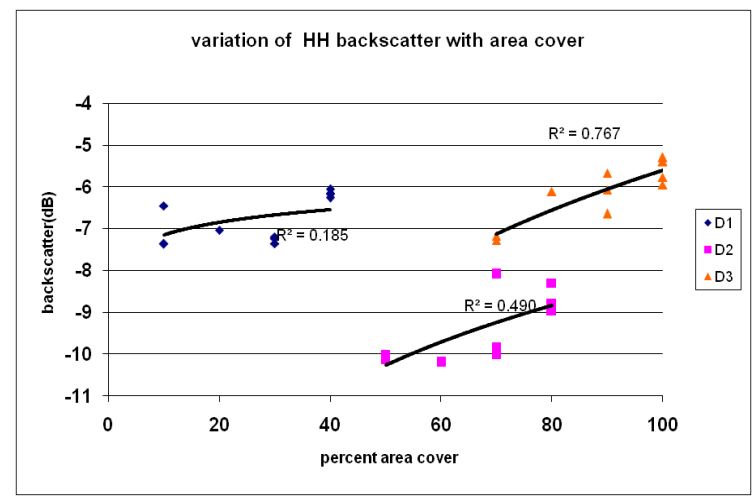

(c)

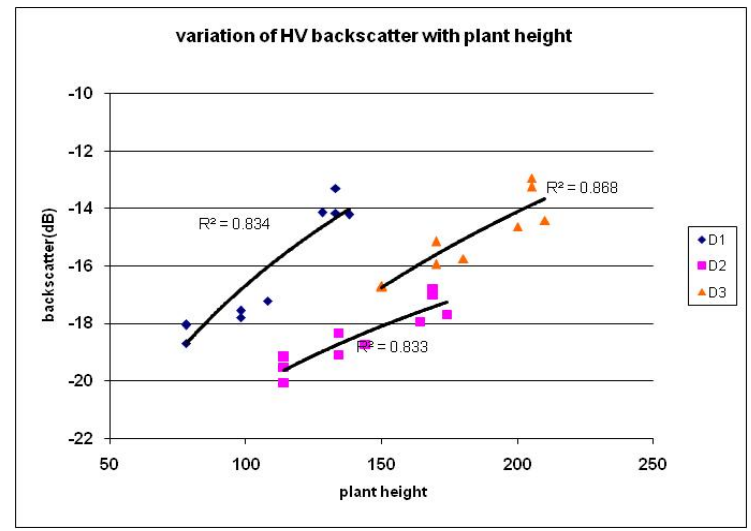

(b)

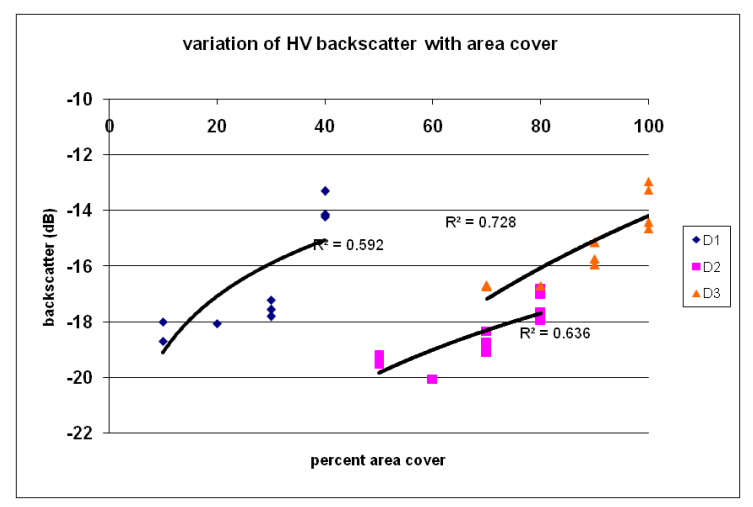

(d)

Figure 3. Variation of backscatter with plant height (cm) (a) (b) and area cover (\%) (c) (d). D1, D2 and D3 denotes the three dates of data acquisition in C-band. 


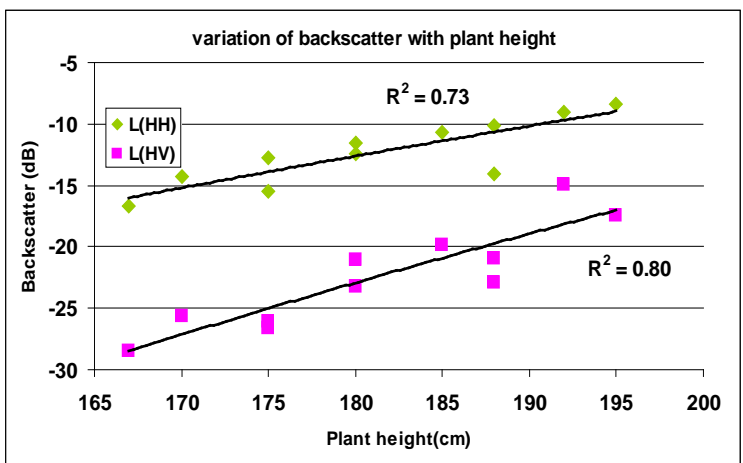

(a)

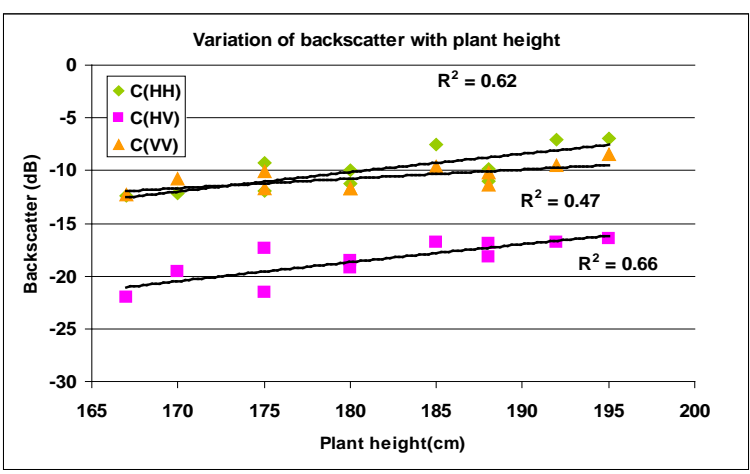

(b)

Figure 4. (a) (b) Plot of HH and HV backscatter at C and L-band vs plant height during mid July (Jute crop) in Murshidabad Dist West Bengal.

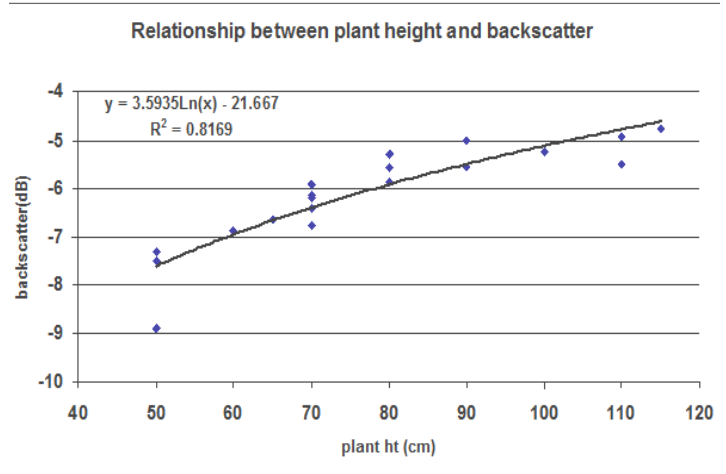

(a)

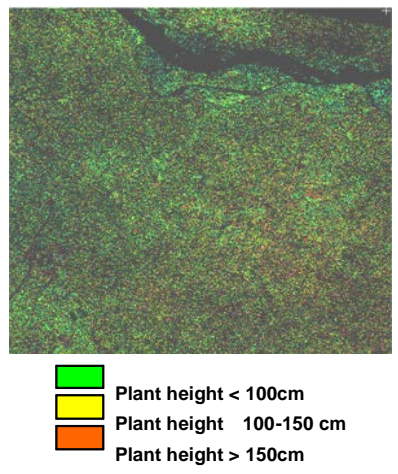

(b)

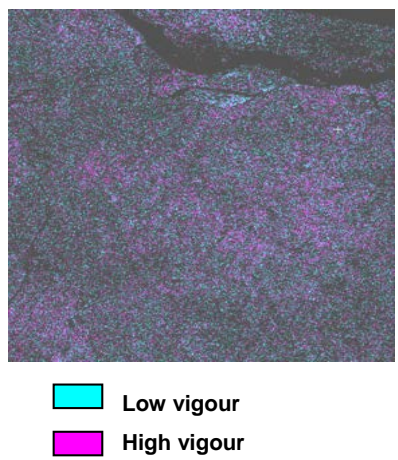

(c)

Figure 5. (a) (b) (c) Height - backscatter relation in C-band, Plant height and vigour map during mid July (Jute crop) in Murshidabad Dist. West Bengal, India.

Plant vigour is computed from difference in cross-polarization ratio and plant height information. Cross polarization ratio changes more (decreases more) for higher change in biomass and vigour. Thus cross-polarization ratio along with crop height map was used to categorize the jute area to low vigour zones (as seen in cyan) and high vigour zones as seen in magenta in Figure 5(c). Biomass was sampled in the field and post classification verification of vigour and crop height has been carried out. A post verification accuracy of $81 \%$ was obtained. Verification with ground truth biomass conformed to higher vigor zones and thus high plant height zones.

The best features to monitor vigor/biomass are HV polarization and cross polarization ratio. When considering HV polarization, for which long stems are dominant, the highest correlations are observed at $\mathrm{L}$ band for high vigour crops (near peak vegetative stage) but moderate correlations are found in C band for entire period finally reduces on third date due to signal saturation. In the double bounce stage of the crop when long erect stems stands upright on smooth flat surface, studying VV-polarization would give meaningful results. These results are in agreement with previous theoretical considerations. These inputs are valuable for monitoring jute growth condition and overall planning. The zonations based on vigour and plant height can be used in the future to decide upon an optimum plan for harvest so as to better utilize the limited resources.

\section{Conclusion}

SAR dual-polarization and dual-frequency data over fields of jute and paddy brought out the advantage of cross polarization and lower frequency for dynamic crop monitoring. High biomass and high density crop of jute could be segregated into zones of height and vigour categories in near mature crop. Observations indicate higher sensitivity of linear cross polarizations in detection of zones based on crop conditions characterized by variations in crop height, vigor and density. Further analysis is planned to quantify this sensitivity as a function of incidence angle and VV-polarization. Other polarimetric parameters from full-polarimetric data will be used to es- 
tablish the dominant sources of scattering. These preliminary results indicate that SAR sensors like RADARSAT-2 could provide useful crop condition information for use in land management planning. In conclusion, HV backscatter and cross-polarization ratio show the maximum difference between bare and vegetated fields, so that they are expected to have the best sensitivity to vigour and hence biomass. The HV polarization is also found to increase the classification accuracy especially when temporal datsets are limited.

\section{Acknowledgements}

The authors are grateful to Dr. A.S. Kirankumar, Director SAC, for his support and guidance. Part of the work was carried out as a part of FASAL project and the authors are highly grateful to Dr. J.S. Parihar, Mission Director, EOAM/Deputy Director, EPSA, for his encouragement during the period of investigation.

\section{References}

[1] Agricultural Situation in India, 2004. Publication Division. Directorate of Economics and Statistics, Department of Agriculture and Co-operation, Ministry of Agriculture. Government of India.

[2] Agricultural situation in India, 2005. Publication Division. Directorate of Economics and Statistics, Department of Agriculture and Co-operation, Ministry of Agriculture. Government of India.

[3] CMIE (Centre for Monitoring Indian Economy Private Limited) Agriculture March 2006, Economics Intelligence Service.

[4] Attema, E.P.W. and Ulaby, F.T. (1978) Vegetation Modeled as a Water Cloud. Radio Science, 13, 357-364. http://dx.doi.org/10.1029/RS013i002p00357

[5] Le Toan, T., Lopes, A. and Huet, M. (1984) On the Relationship between Radar Backscattering Coefficient and Vegetation Canopy Characteristics. Proceedings of International Geoscience and Remote Sensing Symposium 1984, ESA special publication, Strasburg, 155-160.

[6] Shanmugan, K.S., Ulaby, F.T., Narayanan, V. and Dobson, C. (1983) Identification of Corn Fields Using Multidate Radar Data. Remote Sensing of Environment, 13, 251-264. http://dx.doi.org/10.1016/0034-4257(83)90043-3

[7] Brisco, B., Brown, R.J., Gairns J.G. and Snider, B. (1992) Temporal Ground Based Scatterometer Observations of Crops in Western Canada. Canadian Journal of Remote Sensing, 12, 2283-2298. http://dx.doi.org/10.1080/01431169108955258

[8] Levine, D.M. and Karam, M.A. (1996) Dependence of Attenuation in a Vegetation Canopy on Frequency and Plant Water Content. IEEE Transactions on Geoscience and Remote Sensing, 34, 1090-1096. http://dx.doi.org/10.1109/36.536525

[9] Hoogeboom, P. (1983) Classification of Agricultural Crops in Radar Images. IEEE Transactions on Geoscience and Remote Sensing, GE-23, 29-336. http://dx.doi.org/10.1109/TGRS.1983.350562

[10] Kuroso, T., Suitz, M., Fujita, K. and Chiba, M.T. (1993) Rice Crop Monitoring with ERS-1 SAR-A First Year Result. Proceedings of 2nd ERS-1 Symposium, Hamburg, 11-14 October 1993, ESA SP-361, 97-102.

[11] Aschbacher, J., Pongsrihadulchai, A., Karnchanasutham, S., Rodprom, C., Paudya, D.R. and Le Toan, T. (1995) Assessment of ERS-1 SAR Data for Rice Crop Mapping and Monitoring. International Geoscience and Remote Sensing Symposium IGARSS '95, “Quantitative Remote Sensing for Science and Applications”, 3, 2183-2185.

[12] Premlatha, M. and Rao, P.P.N. (1994) Crop Acreage Estimation Using ERS-1 SAR Data. Journal of Indian Society of Remote Sensing, 22, 139-147. http://dx.doi.org/10.1007/BF03024775

[13] Le Toan, T., Ribbes, F., Floury, N., Wang, L., Kong, J.A., Kurosu, T. and Fujita, M. (1997) Rice Crop Map Ping and Monitoring Using ERS-1 Data Based on Experiment and Modeling Results. IEEE Transactions on Geoscience and Remote Sensing, 35, 41-56. http://dx.doi.org/10.1109/36.551933

[14] Parihar, J.S., Panigrahy, S. and Chakraborty, M. ADRO Document. Paddy Rice Monitoring with Radarsat 1.

[15] Panigrahy, S., Manjunath, K.R., Chakraborty, M., Kundu, N. and Parihar, J.S. (1999) Evaluation of RADARSAT Standard Beam Data for Identification of Potato and Rice Crops in India. ISPRS Journal of Photogrammetry and Remote Sensing, 54, 254-262. http://dx.doi.org/10.1016/S0924-2716(99)00020-9

[16] Chakraborty, M., Manjunath, K.R., Panigrahy, S., Kundu, N. and Parihar, J.S. (2005) Rice Crop Parameter Retrieval Using Multi-Temporal, Multi-Incidence Angle Radarsat SAR Data. ISPRS Journal of Photogrammetry and Remote Sensing, 59, 310-322. http://dx.doi.org/10.1016/j.isprsjprs.2005.05.001

[17] Macelloni, G., Paloscia, S., Pampalonia, P., Ruisia, R., Dechambre, M., Valentin, R., et al. (2002) Modelling Radar Backscatter from Crops during the Growth Cycle. Agronomie, 22, 575-579. http://dx.doi.org/10.1051/agro:2002040 
[18] Wang, C., Wu, J., Zhang, Y., Pan, G., Qi, J. and Salas, W.A. (2009) Characterizing L-Band Scattering of Paddy Rice in Southeast China With Radiative Transfer Model and Multitemporal ALOS/PALSAR Imagery. IEEE Transactions on Geoscience and Remote Sensing, 47, 988-997.

[19] Chakraborty, M., Panigrahy, S. and Sharma, S.A. (1997) Discrimination of Rice Crop Grown under Different Cultural Practices Using Temporal ERS-1 Synthetic Aperture Radar Data. ISPRS Journal of Photogrammetry and Remote Sensing, 52, 183-191. http://dx.doi.org/10.1016/S0924-2716(97)00009-9

[20] Panigrahy, S., Chakraborty, M., Sharma, S.A., Kundu, N., Ghose, S.C. and Pal, M. (1997) Early Estimation of Rice Acreage Using Temporal ERS-1 Synthetic Aperture Radar Data-A Case Study for Howrah and Hughly Districts of West Bengal, India. International Journal of Remote Sensing, 18, 1827-1833. http://dx.doi.org/10.1080/014311697218133

[21] Haldar, D., Patnaik, C. and Chakraborty, M. (2007) Jute Crop Identification Using Multi-Temporal SAR, Scientific Report, EOAM/SAC/RESIPA/FASAL-TD/29/2007.

[22] Patnaik, C. and Haldar, D. Jute Acreage Estimation Using Multi-Temporal Radarsat SAR data. Scientific Report, EOAM/SAC/RESA/FASAL-TD/35/2008.

[23] Haldar, D., Patnaik, C., Chakraborty, M., Paul A. and Kundu, N. (2011) Identification of Tall Fibre Crop (Jute) Using Multi-Temporal RADARSAT Data in Rainfed Areas of Eastern Indogangetic Plain. Asian Journal of Geoinformatics, Vol. 11, No.3.

[24] Singh, C. (2000) Principles for Raising Field Crops.

[25] McNairn, H., Decker, V. and Murnaghan, K. (2002) The Sensitivity of C-Band Polarimetric SAR to Crop Condition. IEEE Transactions on Geoscience and Remote Sensing, 3, 1471-1474.

[26] de Matthaeis, P., Ferrazzoli, P., Schiavon, G. and Solimini, D. (1995) Crop Type Identification and Biomass Estimation by SAR. IEEE Transactions on Geoscience and Remote Sensing, 11, 957-959.

[27] Zhang, Y., Wang, C. and Zhang, Q. (2011) Identifying Paddy Fields with Dual-Polarization ALOS/PALSAR Data. Canadian Journal of Remote Sensing, 37, 103-111 


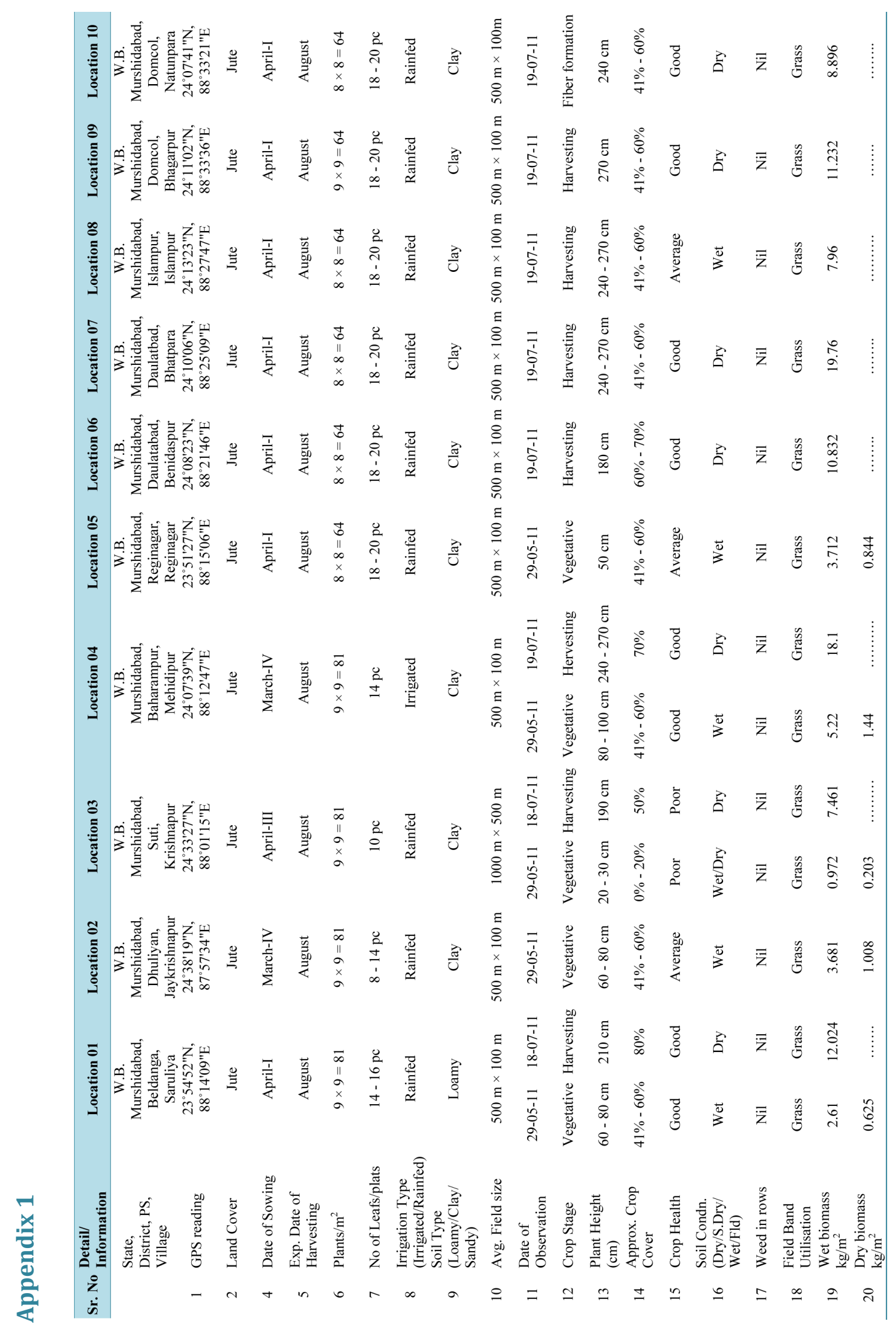

